\title{
Sobre uma teoria da expectativa
}

\author{
Luiz Carlos Cagliari*
}

\begin{abstract}
Resumo
O presente trabalho apresenta como se pode ter uma teoria semântica cognitiva da ideia de expectativa encontrada no processo de comunicação linguística. Encontra-se essa ideia comumente em conversas, diálogos, em textos orais e literários, o que a caracteriza como um fato semântico de uso muito comum. Uma análise geral mostra que a ideia de expectativa é muito mais importante para os estudos semânticos e discursivos do que se costuma pensar. Uma análise mais profunda mostra que a linguagem precisa da ideia de expectativa como motivador de seu uso. Desse modo, a expectativa está na base de todo processo de comunicação linguístico. As línguas dispõem de muitas palavras e expressões que introduzem uma expectativa na comunicação, como a própria palavra expectativa, expressões como eu acho que... e até estruturas sintática e prosódicas como uma pergunta. A expectativa pode estar na mente do falante ou na mente do ouvinte ou na mente de todas as pessoas envolvidas numa comunicação linguística. A expectativa pode ser também uma noção estabelecida formalmente através de regras ou de costumes na sociedade. A formulação de uma teoria da expectativa tornou-se mais viável com o desenvolvimento da semântica cognitiva nas últimas décadas. A noção de frame é, talvez, a que melhor explique a expectativa.
\end{abstract}

Palavras-chave: Expectativa. Comunicação. Frame. Linguística Cognitiva.

\section{A mente e a semântica cognitiva}

A mente humana tem sido objeto de investigação desde os antigos filósofos. O racionalismo aristotélico e o idealismo platônico podem ser vistos também como um estudo sobre a mente humana através da linguagem. Ligado à linguagem está a ideia de pensamento. O local onde ocorre o pensamento tem sido nomeado como psiquê, alma, mente, intelecto, sede do pensamento, faculdade da linguagem. A própria palavra mente remonta ao latim. Dificilmente alguém imaginaria o ser

1 Livre Docente pela Universidade Estadual de Campinas (UNICAMP), onde atuou como Professor Titular (1990). Pós-doutor pelas Universidades de Londres (1987) e de Oxford (2003). Foi professor Adjunto MS-5 da Universidade Estadual Paulista Júlio de Mesquita Filho (UNESP), campus Araraquara. O autor agradece ao CNPq pelo suporte financeiro de uma bolsa PQ, processo 304170/2013-5 e a Ana Eliza B. O. Baptista 
humano sem uma inteligência, porque é a racionalidade que distingue o ser humano dos demais seres vivos. Em razão disso, ao longo da história da Humanidade, muito se investigou e se disse a respeito da mente. Em meio a muitos estudos sérios, encontram-se também, às vezes, algumas afirmações bizarras. Os filósofos e os religiosos são os que mais se preocuparam com a mente (alma). Os filósofos procuram uma lógica para explicar a vida terrena e os religiosos procuram uma vida além da morte. Só mais recentemente a medicina, a genética, a psicologia e a linguística passaram a se interessar particularmente pela mente como uma ação do cérebro ou mesmo do DNA.

Teoricamente, podem-se formular algumas hipóteses a respeito do cérebro e da mente. Pode-se dizer que o cérebro apenas se conecta com o mundo exterior fora das pessoas, através dos sentidos, controlando o processo da vida bioquímica. O cérebro seria uma espécie de HD com uma enorme capacidade de memória e de processamento que lhe é peculiar. A mente seria uma espécie de software do processo da vida, também chamado de pensamento. Assim, podemos dizer que a mente é uma faculdade que processa a linguagem, porque o pensamento é a linguagem e a linguagem é a expressão verbal do pensamento. Porém, onde está a mente? Como ela é? Como é complicado atribuir ao cérebro a faculdade do pensamento ou da linguagem, uma saída (provisória) tem sido inventar a mente, através de um axioma. Com isso, é possível fazer hipóteses sobre sua natureza e funções a partir de uma observação de como a linguagem funciona.

Com as investigações modernas da biofísica e da ciência da cognição, o que se entende por mente humana tem sido caracterizado num nível de detalhes muito grande, seja tendo em vista o fator biológico (cérebro e mente), seja tendo em vista o fator linguístico. A contribuição da linguística cognitiva e, em particular, da semântica cognitiva revolucionou o modo como analisamos e compreendemos muitos fenômenos semânticos, como a metáfora, por exemplo.

Da década de 70 do século passado até hoje, a linguística cognitiva desenvolveuse muito, produzindo uma grande quantidade e uma grande variedade de trabalhos sob essa perspectiva. Uma resumida lista de obras, como sugestão, inclui obras como LAKOFF; JOHNSON, 1980; FILLMORE, 1982; LANGACKER, 1987; JOHNSON, 1990; FILLMORE; ATKINS, 1992; SEARLE, 1992; FAUCONNIER, 1994; FAUCONNIER, 1999; LAKOFF; JOHNSON, 1999; WILSON; KEIL, 1999; LAKOFF, 2000; TALMY, 2000; FAUCONNIER; TURNER, 2002; KÖVECSES, 2006; EVANS; GREEN, 2006; GEERAERTS; CUYKEN, 2007; AVERBECK, 
2010. Algumas obras têm um caráter introdutório ou trazem considerações de natureza histórica. Outras apresentam pesquisas sobre tópicos específicos, em geral, introduzindo novas teorias cognitivas para fatos linguísticos.

Com esses e outros trabalhos, acabamos descobrindo que pensamos através de mecanismos que antes pareciam insuspeitos. A linguagem corporificada, os frames e os scripts, o fenômeno de blending, a teoria dos espaços mentais trouxeram uma reviravolta nos estudos semânticos das últimas décadas. A teoria dos sistemas complexos, desenvolvida na teoria quântica, a entropia dos sistemas complexos, os processos de categorização e de formação de matrizes, somaram-se às teorias psicológicas dos protótipos. Somando o antigo com o novo, os conhecimentos que temos da mente humana mostram que já sabemos muito a respeito dela, com grande grau de segurança. Começa-se a ter a sensação de que resta pouco para saber.

Colocada a questão como acima, parece temerários propor algo novo. $\mathrm{Na}$ verdade, o que se propõe neste trabalho, estudando a expectativa, não é um fenômeno novo, mas um modo diferente de olhar algo que sempre esteve lá, mas que, com relação a ele, pouca atenção tem sido prestada de modo específico e minucioso.

\section{O significado linguístico na semântica}

Historicamente, podemos dividir os estudos de semântica, compreendendo todos os seus aspectos, em três grupos: estudos do literal; estudos do não dito e estudos do significado na mente.

O primeiro trata do significado lexical e sintático, bem como da lógica e da etimologia. Pode-se fazer um dicionário, estabelecer funções sintáticas com papéis temáticos, mostrar uma teoria lógica da linguagem e estudar um texto científico (LYONS, 1996). Todos esses estudos dependem do que é dito, focando principalmente o que se costuma chamar de sentido literal ou expresso pelas palavras dos enunciados.

O segundo grupo tem a ver com a semântica argumentativa, com os atos de fala (AUSTIN, 1975; SEARLE, 1992), com a dimensão pragmática do uso da linguagem (LEVINSON, 1983), quando ocorre algum significado pressuposto, acarretado ou conotativo, apoiado em elementos do sistema da língua. Por exemplo, quando alguém diz "Helena parou de escrever poesias aos 18 anos", 
subentende-se que "ela escrevia poesias até os 18 anos" e mais "que ela não escreveu mais poesias depois dos 18 anos". O pressuposto (DUCROT, 1972) tem uma estrutura "lógica" embutida no próprio sistema da língua, seguindo regras bem definidas. Os atos de fala têm a ver com a mistura de fala e de realização de um ato socialmente estabelecido, como quando um juiz diz: "Eu te condeno a um ano de prisão por crime de peculato".

O terceiro grupo estuda como o significado se estrutura e funciona na mente do falante e do ouvinte. Nas últimas décadas, a Semântica Cognitiva vem revelando como a mente humana trabalha com o conhecimento, mostrando uma relação muito estreita entre significado linguístico, mundo e falante. Ideias tradicionais como a arbitrariedade do processo de referência na constituição do signo e outras foram redefinidas a partir do trabalho executado pela mente. A metáfora passou de uma simples figura de linguagem para um mecanismo definidor do sentido das expressões linguísticas (LAKOFF; JOHNSON, 1980). Outros autores apresentaram outros mecanismos das operações semânticas da mente, como os frames, o blending, os espaços mentais, a teoria da corporificação da mente, etc. (FILLMORE, 1982; FAUCONNIER, 1999; FAUCONNIER; TURNER, 2002). Mesmo dentro da Semântica Cognitiva, os estudos do significado ficaram restritos ao que se diz, como se diz, e ao que se pretendia dizer. As conexões entre a mente, a fala e o mundo continuam constituindo o objeto da semântica nas suas diversas teorias e abordagens. Entretanto, os meandros cognitivos da mente apresentam pensamentos coletivos ou individuais que são, primeiramente, elaborados na mente, e lá podem ficar para sempre ou serem, eventualmente, revelados através da fala. Nesse contexto, encontramos a noção de expectativa tal qual definida neste trabalho.

\section{A ideia de expectativa sob investigação}

Como mencionado anteriormente, a ideia de expectativa aparece frequentemente em considerações semânticas sobre o significado. Entretanto, sua natureza e funções não têm sido estudadas na devida medida. Com as investigações sobre a mente a partir da linguagem (LAKOFF; JOHNSON, 1980; FILLMORE, 1982; PINKER, 1995), algumas palavras e fenômenos linguísticos passaram a merecer uma atenção especial. Apesar de a noção de expectativa aparecer pouco em estudos semânticos, na década de 60 e 70 do século passado, encontram-se 
alguns trabalhos em que a ideia de expectativa desempenha papel importante de como entendemos a linguagem. Um resumo desses trabalhos foi apresentado por Debora Tannen (1979). Ela mesma apresenta um estudo próprio, mostrando como falantes de inglês e de grego interpretam um texto. Seu estudo é feito dentro de uma perspectiva ligada ao conceito semântico de frame. Ela conclui, dizendo:

I have shown that the notion of script, frame, and schema can be understood as structures of expectation based on past experience, and that these structures can be seen in the surface linguistic form of the sentences of a narrative. Furthermore, the structures of expectation which help us process and comprehend stories serve to filter and shape perception. That is why close analysis of the kinds of linguistic evidence I have suggested can reveal the expectation or frames which create them (TANNEN, 1979, p. 179). ${ }^{1}$

Fillmore (1982) também usa a noção de frame para explicar a expectativa:

Knowing that a text is, say, an obituary, a proposal of marriage, a business contract, or a folktale, provides knowledge about how to interpret particular passages in it, how to expect the text to develop, and how to know when it is finished. It is frequently the case that such expectations combine with the actual material of the text to lead to the text's correct interpretation. And once again this is accomplished by having in mind an abstract structure of expectations which brings with it roles, purposes, natural or conventionalized sequences of event types, and all the rest of the apparatus that we wish to associate with the notion of 'frame' (FILLMORE, 1982, p. 117). ${ }^{2}$

Estudando como os discursos retóricos de natureza persuasiva devem ser recebidos, Michael Burgoon e Gerald R. Miller (1985) criaram uma teoria rotulada de LET (Language Expectancy Theory ou Teoria da Expectativa Linguística). Eles

1 Tradução: Mostrei como as noções de script, frame e schema podem ser entendidas como estruturas de expectativa baseadas em experiências passadas, e como essas estruturas podem ser vistas na forma de superfície linguística de sentenças de uma narrativa. Além disso, as estruturas da expectativa que nos ajudam a processar e a compreender as histórias servem para filtrar e moldar a percepção. É por isso que uma análise minuciosa dos tipos de evidência que eu sugeri pode revelar as expectativas ou os frames que as criaram (TANNEN, 1979: 179).

2 Tradução: Sabendo que um texto é um obituário, uma proposta de casamento, um contrato de negócios, uma lenda popular, isso traz conhecimentos de como interpretar uma passagem particular nele, como se espera que o texto se desenvolva e como saber quando terminou. Frequentemente, é o caso que tais expectativas combinem com o material atual do texto para levar a uma interpretação correta do texto. E mais uma vez, isso é realizado tendo na mente uma estrutura abstrata de expectativas que traz com ela regras, intenções, sequências naturais ou convencionalizadas de tipos de ocorrências e todo o aparato restante que queremos associar à noção de frame (FILLMORE, 1982, p. 117). 
mostram como a linguagem dispõe de regras para que uma comunicação possa acontecer e o discurso retórico ter sua eficácia. Esses conhecimentos ou regras são compartilhados pelo orador e pelo auditório e constituem expectativas de ambas as partes. A existência dessas regras por si só não garante o sucesso do discurso, mas constituem expectativas que devem ser compartilhadas. Vários trabalhos foram feitos a partir dessa teoria (MILLER, 1987; BURGOON, 1995; BURGOON et al., 2002). A abordagem de Burgoon e Miller está voltada apenas para o uso de regras na retórica e, portanto, não estuda exatamente o que apresentamos neste trabalho.

A semântica tradicional tem estudado de modo bastante detalhado o significado linguístico das palavras, das proposições, dos enunciados e até do texto e do discurso. Podemos ver esses estudos em duas partes: aquela que trata do significado literal e aquela que trata do significado não dito, mas expresso através de estruturas linguísticas, como o pressuposto, a conotação, etc. A outra parte se subdivide em duas: uma oriunda dos estudos pragmáticos, que acrescentam sentidos a partir do uso, como as implicaturas e os atos de fala; a outra, que estuda o significado linguístico como modelos cognitivos idealizados na mente.

O objetivo deste trabalho é um estudo da noção de expectativa. Como o rótulo "expectativa" tem muitos sentidos e aplicações, é preciso distinguir algumas coisas. Preliminarmente, assume-se que o objeto do presente estudo é uma ideia que reside na mente das pessoas, ou seja, é uma ideia pensada, mas não necessariamente falada. Numa definição estreita, trata-se de um construto da mente que não precisa ser explicitado, mas cuja realidade é uma espécie de "conversa" da mente consigo própria, com um objetivo de produzir e interpretar uma realidade ou um discurso. Sendo a linguagem uma atividade da mente, uma expectativa pode aparecer explícita ou implícita numa mensagem. É comum o falante se garantir quanto ao valor de verdade do que diz, indicando qual é sua expectativa com relação a isso, por exemplo, quando atenua o valor de verdade do que diz, como em (1):

(1) Eu acho que o dólar vai baixar.

Por razões metodológicas, assume-se que a ideia de expectativa, objeto deste trabalho, não se confunde com significados e sentidos - semânticos e pragmáticos - tradicionalmente analisados pela linguística. Desse modo, estão de fora interpretações de pressuposição, implicatura, implícitos, subentendidos, sentido das entrelinhas, uso argumentativo de inferências, conotações, processos de construção de sentido no discurso, o conhecimento do mundo, atos de fala, 
máximas conversacionais, conhecimento enciclopédico e, obviamente, o significado literal das palavras no léxico. $\mathrm{O}$ que todos esses itens têm em comum é o fato de estarem ligados necessariamente à fala, ao texto, ao enunciado. $\mathrm{Ou}$, ainda, todos esses fatores semânticos precisam se ancorar num enunciado, num discurso. Eles não podem ocorrer só na mente, como pode acontecer com a ideia de expectativas. Há, na fala, algum elemento explícito ou implícito que justifica as diferentes interpretações semânticas mencionadas acima.

Numa abordagem semântica tradicional, encontramos a ideia de expectativa explícita ou camuflada em muitos tipos de teorias semânticas e de trabalhos. Os atos de fala (Austin, 1975) é um caso claro da presença de uma expectativa. $O$ falante tem a clara intenção de produzir um ato com sua fala, reconhecido com um poder legal por uma sociedade. Por outro lado, o ouvinte sabe das implicações daquela fala, também reconhecendo o fato como legal. Para que o ato de fala se consuma, é preciso que o falante e o ouvinte compartilhem das mesmas expectativas, como quando o juiz de paz diz:

(2) Eu os declaro marido e mulher.

Ações pragmáticas da linguagem costumam ser dependentes de expectativas por parte dos envolvidos. Por exemplo, o fato de alguém ensinar supõe por parte de quem ensina que é possível transmitir ensinamentos e, por parte de quem aprende, que é possível aprender. Caso contrário, o ensino e a aprendizagem não fariam sentido.

Muitos linguistas costumam salientar que todo ato de comunicação participa de um processo de interação (BAKHTIN, 1979). Subjacente a toda interação linguística, há um compartilhamento de expectativas por parte de quem produz o texto e por parte de quem o interpreta. A ponte que liga um autor ou falante e um leitor ou ouvinte é o fato de que ambos estão envolvidos em experiências antigas ou atuais, que se tornaram expectativas. $\mathrm{Na}$ verdade, toda comunicação começa com uma expectativa por parte do falante. Por outro lado, todo processo de compreensão começa com expectativas do ouvinte. São as expectativas que criam condições para uma conversa e para um diálogo. Sem expectativas, essas atividades ficam sem sentido. Como diz o ditado popular "são palavras ao vento".

Dentro do contexto da Gramática Gerativa, quando Chomsky (1965) refere-se à intuição do sujeito falante, está reconhecendo que o conhecimento interiorizado do falante com relação ao sistema de sua língua cria expectativas gramaticais. O reconhecimento de um acerto ou de um erro gramatical só é possível porque 
a língua tem um sistema e os falantes usam esse sistema como expectativas de realizações linguísticas corretas (ROOT, 1976).

Quando se aprende uma palavra, além dos fonemas, alofones, morfemas e dos significados associados, acrescentamos informações de uma estrutura prosódica, como a ordem dos segmentos, a tonicidade, a divisão silábica, etc. Além disso, cria-se uma expectativa de uso que permite dizer e avaliar a realização correta ou incorreta da palavra, não apenas com relação à sua integridade lexical, mas também com relação aos sentidos possíveis que pode ter em contextos sociolinguísticos específicos. Veja-se o exemplo abaixo:

(3) Bata levemente na panela.

Embora seja de fácil compreensão o sentido do exemplo (3), isso acontece porque temos certas expectativas de como segmentar e interpretar sequências de sons. Por exemplo, na palavra "levemente", não entendemos a sequência "mente" como se referindo à faculdade do pensamento. Na palavra "panela", não entendemos "pá" (instrumento), mais "nela" (pronome). Porém, reconhecemos sufixo verbal em "bata", sabemos que "panela" é uma palavra feminina no singular, ou seja, identificamos facilmente os morfemas das palavras de uma língua como o português. Isso mostra que a compreensão é uma expectativa com relação ao conhecimento de alguma coisa.

Uma área dos estudos linguísticos que tem trabalhado com a ideia de expectativa, sob vários ângulos, é a Análise do Discurso de linha francesa. A análise dos processos de construção de sentido no discurso se atém à linguagem e não à mente do falante e do ouvinte. Portanto, a ideia de "expectativa" do presente trabalho refere-se a outra realidade, embora possa também servir de base para muitas explicações sobre a enunciação e o discurso. Dentro da Linguística Textual, também se encontram referências de significado que podem ser associadas à ideia geral de expectativa. Talvez a noção mais próxima seja o conhecimento de mundo. Entendemos o mundo e a linguagem somente com os conhecimentos adquiridos.

É comum encontrar em diferentes tipos de discurso (textos ou enunciados simples) a presença de interpretações que fogem do literal e que são criações que trazem a marca da individualidade, mas podem também ser de grupos de pessoas. Todo discurso religioso é desta natureza: acreditamos, temos fé, esperamos que algo aconteça. São expectativas coletivas que dão um significado especial ao discurso religioso. Em grau menor, podemos encontrar essas expectativas também em discursos científicos. Veja os exemplos a seguir: 
(4) Deus dará a vida eterna aos justos.

(5) A Teoria da Relatividade é errada, porque já temos as leis de Newton.

As piadas, os jogos de palavras, os chistes, as adivinhações e coisas semelhantes existem como tais porque criam uma expectativa na mente do ouvinte, a qual é, depois, frustrada com a revelação final de como se deve entender o que foi dito, como na seguinte piada:

(6) Da janela de um hospício, um louco viu que uma pessoa trocava um pneu do carro, quando percebeu que os parafusos caíram em um bueiro. Sem saber o que fazer, o dono do carro começou a lamentar. O louco foi até ele e disse: "Por que você não tira um parafuso das outras três rodas e os coloca na roda que ficou sem parafusos?". O motorista achou a ideia genial e perguntou: "Mas você não é um louco?" O louco respondeu: "Eu sou louco, mas não sou burro!”.

As pessoas criam hipóteses na mente que são deduções, ou seja, associação de ideias com uma finalidade explicativa. Algumas deduções são consequências diretas do que foi dito ou pressuposto, mas algumas são expectativas que só fazem sentido na mente de quem falou ou ouviu. A estranheza causada por alguns enunciados mostra que temos uma lógica de entendimento da realidade. Essa lógica é uma expectativa coletiva, compartilhada e que é esperada na fala das pessoas. É por isso que (7) é um enunciado estranho (idiota, de mau gosto...)

(7) Você vai a pé ou sem pé?

Os exemplos acima mostram tipos de expressões, enunciados e discursos que induzem expectativas. Eles são motivados por hipóteses, estranhezas ou por uma lógica popular. Além disso, uma expectativa pode ser individual ou coletiva (social). As formas de ideologia são tratadas na mente como expectativas que comandam a ação social. Toda motivação social, política ou religiosa é uma forma de expectativa de determinados grupos de pessoas. Uma análise da história da Humanidade, de um povo e até de uma pessoa mostra que vivemos em função de expectativas individuais ou sociais.

Grice (1989) estabeleceu alguns “princípios cooperativos da conversação”, para mostrar o essencial, mas, ao mesmo tempo, dá a entender os problemas decorrentes da falta de "cooperação" na fala. Esses e outros fatores textuais e conversacionais revelam um cenário comunicativo que é sempre preocupante para o falante e para o ouvinte. No meio de tantas dúvidas e insucessos comunicativos, aparece a figura da "expectativa de sentido", de algo não dito, mas que se gostaria de dizer se, em vez de uma conversa sucinta, a troca de informações entre as pessoas pudesse se 
desenvolver em muitos detalhes e considerações. Porque simplificamos o modo como comunicamos, criamos vazios semânticos que podem gerar dúvidas, malentendidos, perplexidades, etc. numa batalha entre expectativas e interpretações das mensagens na comunicação.

A área da prosódia tem trabalhado com as atitudes do falante. Do ponto de vista físico, a prosódia é entendida com estudo dos fenômenos fonéticos suprassegmentais, como a duração, a altura melódica, o ritmo, a entoação, a qualidade de voz, entre outros (CAGLIARI, 2007). Do ponto de vista do significado, as atitudes dos falantes revelam sentidos não literais, mas compartilhados pelo sistema da língua, envolvendo, em geral, as emoções e sentimentos semelhantes. As atitudes dos falantes aparecem na fala e são carreadas pelos elementos linguísticos dos enunciados. Uma pessoa é grosseira quando fala, porque imprime à sua fala características prosódicas da grosseria. Através da prosódia, pode-se dizer um enunciado com sentido suspensivo, inacabado, deixando ao interlocutor preencher uma lacuna semântica não dita.

Existe um fato semântico, que podemos definir como expectativa que, às vezes, recebe o rótulo de conotação, de sentido pressuposto, de sentido assumido pelo falante ou pelo ouvinte, o qual é usado, em geral, para explicar desvios de interpretação. Esses rótulos abrangem vários fenômenos semânticos além da ideia de expectativa e estão sempre ligados a uma expressão linguística. São interpretações decorrentes de outras, expressas através de palavras ou de estruturas já definidas na semântica do enunciado.

A surpresa é uma interpretação de algo que não deu certo, devido à ignorância diante da realidade ou, simplesmente, porque se esperava que as coisas fossem diferentes. Portanto, há expectativas de vários tipos e graus. Há expectativas que são facilmente compartilhadas por grupos de pessoas e expectativas que são elaboradas na mente de indivíduos e podem ficar lá para sempre sem aparecerem na fala. Há expectativas que acabam mostrando uma realidade acontecida, como há expectativas que revelam uma frustração do que a pessoa pensava. Há expectativas esperançosas, muitas vezes, fruto da imaginação e, não raramente, de superstição e de desejos. Há expectativas positivas e negativas, que se realizam ou não.

$\mathrm{O}$ resultado de mal-entendidos vem mais do preenchimento das expectativas por parte do ouvinte e, mais raramente, da ambiguidade, da vagueza ou de outras ocorrências semânticas ligadas às palavras (CANÇADO, 2005). O mal-entendido 
proveniente das expectativas é mais sutil e mais difícil de ser discutido, mas nem por isso deixa de ser preocupante na vida das pessoas e das sociedades.

Os modelos da semântica cognitiva organizam nosso conhecimento de mundo em categorias ou grupos de ideias associativas, como os frames, os esquemas mentais, os scripts, entre outros (ABREU, 2010; FERRARI, 2011). Certamente, assim como os conhecimentos de mundo dão sentido e coerência à comunicação linguística, também servem de suporte para qualquer tipo de expectativa na mente ou no discurso das pessoas. Um uso típico dos conhecimentos de mundo armazenados linguisticamente na mente das pessoas é a inferência, ou seja, quando se estabelece uma relação não dita entre dois discursos ou enunciados. A intencionalidade é outro exemplo: o falante procura produzir o "melhor" texto para seu ouvinte, para que as ideias do ouvinte se identifiquem com as ideias do falante. Apesar de tais desejos e das ferramentas comunicativas da linguagem, nem sempre o resultado é o esperado pelo falante ou pelo ouvinte.

\section{Mais algumas considerações para uma teoria da expectativa}

As considerações acima mostram alguns elementos com os quais podemos construir uma teoria da expectativa, captando um sentido que, tradicionalmente, costuma aparecer misturado com outros. Essa é a razão pela qual esse aspecto do significado linguístico das palavras tem ficado pouco explorado e é, em geral, interpretado juntamente com outros sentidos que as palavras e os enunciados têm.

Os pensamentos são elaborados nas mentes das pessoas de modo individual ou na mente coletiva da sociedade. Na mente dos indivíduos, a expectativa pode ser apenas uma memória, enquanto não for traduzida em fala. Na mente coletiva, será sempre uma memória social aceita por consenso ou por documentos históricos.

Portanto, a expectativa, a que se refere este trabalho é uma invenção mental, motivada por razões da vida das pessoas e da sociedade em função da eficácia do processo de comunicação. A noção de expectativa tem a ver com a eficácia da comunicação, sendo um elemento motivador para sua realização. É um requisito necessário para a formulação de um pensamento e para a sua transmissão. Com relação à enunciação, a expectativa pode estar na mente do falante ou do interlocutor.

Uma característica especial associada à ideia de expectativa é sua relação com a noção de tempo, uma vez que a expectativa espera pela realização de um 
fato a ela associado (CAGLIARI, 2008; IAGALLO, 2014). A expectativa é um pensamento em função do tempo passado ou futuro com relação ao momento da enunciação. Não existe expectativa cujos fatos se deem no presente da enunciação. Ou seja, não se constrói uma expectativa no exato momento em que se fala. Ela precisa vir antes. Um enunciado como (8) é agramatical:

(8) *Eu penso que você traz o martelo.

Porém, pode aparecer a coocorrência de verbos no presente quando o sentido do enunciado mostra uma ação que costuma se repetir, como em (9) e (10):

(9) Eu acho que você não pensa em mim.

(10) Certamente, você não está me entendendo.

É da natureza das palavras que introduzem uma expectativa utilizar de fatos já acontecidos ou que irão acontecer, a respeito dos quais se faz um julgamento de valor, como nos exemplos abaixo. Portanto, embora aparentemente possa parecer que há uma expectativa concomitante com o tempo presente da enunciação, por causa do uso de verbos no presente dentro do enunciado, essa é uma ideia falsa, porque só se pode criar uma expectativa com algo que já aconteceu ou que se supõe que irá acontecer, como mostram os exemplos a seguir:

(11) Eu penso que eu estou com dengue.

(12) Eu estou achando que estou com dengue.

(13) Eu acredito que comer berinjela faz bem.

No uso comum, a ideia de expectativa é usada para explicar desvios de interpretação com relação a fatos reais ou imaginários como no exemplo (14):

(14) A minha expectativa era que não chovesse durante o churrasco.

Como choveu, a minha previsão não se realizou. Os dois fatos ocorreram no passado. A expectativa pode ser formulada no passado, referindo-se a uma ação no futuro, que ainda não aconteceu como em (15)

(15) Eu acho que não vai chover amanhã.

O momento da enunciação, como é um momento fluido, que logo se torna passado, permite criar uma expectativa. Neste caso, a ação referida acontecerá no futuro, com relação ao tempo da enunciação. Uma expectativa é um pensamento que se projeta num futuro. A expectativa mostra que a mente não só guarda lembranças e recordações do passado, mas pode criar uma situação de vida mental num futuro, como se a pessoa vivesse uma espécie de ficção científica com dados de sua memória. Há uma explicação idealista interessante nesse sentido: a realidade se apresenta como lembranças do passado, porque o futuro não aconteceu e o 
presente é apenas um portal para o passado. O presente está se transformando em passado a todo instante. Quando vamos falar do presente, ele já é passado. Nesse cenário de representações temporais, a expectativa é um esforço para projetar a mente no futuro.

A surpresa é uma reação na falta de uma expectativa. Depois que um fato acontece, a surpresa só pode ser explicada através da existência não revelada de uma expectativa. Há expectativas que acabam mostrando uma realidade acontecida, como há as que revelam uma frustração do que a pessoa pensava. Há expectativas esperançosas, muitas vezes, fruto da imaginação e, não raramente, de superstição, de crendice ou de desejos. Muito do que se diz é dito através de expectativas, porque o falante não gostaria de dizer uma verdade diretamente. O ouvinte pode apelar para uma expectativa para se desculpar ou mesmo para recriminar o seu interlocutor. Enfim, a expectativa permeia grande parte do uso da linguagem no processo comunicativo. Aparece de modo mais saliente na interação linguística, nos diálogos, às vezes de forma velada.

Do ponto de vista do significado, uma expectativa pode ter uma afirmação explícita ou implícita. Do ponto de vista do falante, encontram-se palavras e expressões que são usadas para sinalizar a presença de uma expectativa na mensagem, como: admiração, desejo, esperança, eu acho que, note que, veja, suspense, confiança, pessimismo, otimismo, prever, probabilidade, profecia, etc. Do ponto de vista do ouvinte: frustração, frustrante, inacreditável, expectativa, desapontamento, falhar, inesperado, lamentar, blefe, ilusão, rejeitado, desilusão...

O presente trabalho traz apontamentos para se construir uma teoria semântica cognitiva da expectativa. Enquanto não se define uma teoria específica sobre o tema, as pesquisas apoiam-se, metodologicamente, em estudos da Semântica Cognitiva. A própria ideia de expectativa ainda precisa de uma definição mais exata. Dada a abrangência do fenômeno, à medida que novos exemplos forem analisados, mais definidas ficam a noções associadas ao tema. A análise dos exemplos deverá associar os fatos das línguas às análises linguísticas dos processos de idealização da mente, dentro de uma perspectiva cognitiva.

\section{Introdutores da Ideia de Expectativa}

Há um conjunto de palavras e de expressões que se caracterizam pelo fato de sinalizarem aos usuários que existe uma expectativa que vem em anexo à 
mensagem, ou que indica que o falante tem algo a mais na sua comunicação, ou mesmo que o interlocutor procurou preencher para melhor compreender a mensagem, a partir de sua experiência linguística e de vida. A própria palavra expectativa existe com essa função. Um levantamento dos usos dessa palavra mostra a natureza e as funções da ideia de expectativa. Mas não é somente a palavra expectativa que se presta a isso.

(16) A minha expectativa é que a festa aconteça sem problemas.

(17) A expectativa dele não aconteceu.

(18) Todos tinham a mesma expectativa.

(19) As células-tronco criaram uma expectativa de imortalidade.

O primeiro exemplo - (16), acima - mostra uma expectativa explicitada na expressão festa sem problemas. A palavra expectativa tem o sentido de desejo. O segundo exemplo, (17), mostra um comentário sobre o primeiro exemplo (16) e significa uma frustração. Mas o falante desse segundo exemplo não tornou explícito qual era a expectativa. O exemplo (18) refere-se a uma expectativa coletiva, compartilhando o mesmo desejo do exemplo (16). Porém, só quem ouviu o falante do primeiro exemplo sabe do que se trata. O último exemplo (19) é uma afirmação de caráter geral. Neste caso, é mais difícil dizer a origem da expectativa, mas seu sentido ficou explícito na palavra imortalidade associada ao conhecimento de mundo. No exemplo (20) abaixo,

(20) Estou muito pessimista com relação à inflação deste ano.

o falante dispõe de conhecimentos econômicos bem definidos em sua mente, levando em conta muitos fatores socioeconômicos. Esses conhecimentos o levam a ter certa expectativa do tipo "acho que a inflação deve variar de 6.5 a 8.0\%". A comunicação do enunciado (20) pode ter a palavra pessimista preenchida com diferentes graus de expectativas: o economista do Governo acha que a inflação vai variar de 6.5 a $7.0 \%$. O comerciante interpreta a palavra pessimista a seu modo e com sua visão do mundo socioeconômico, esperando uma inflação de 6.5 a 12.0 \%. O Governo pode ter a expectativa de que a variação da inflação é irrelevante. O enunciado dito por um comerciante pode levá-lo a calcular os preços com 12.0 $\%$, para evitar prejuízos futuros. Certamente, o resultado de mal-entendidos vem mais do preenchimento das expectativas por parte do ouvinte e, mais raramente, da ambiguidade, vagueza ou outras ocorrências semânticas ligadas às palavras e às sentenças. O mal-entendido proveniente das expectativas que estão em jogo é mais sutil e mais difícil de ser discutido, mas nem por isso deixa de ser preocupante na 
vida das pessoas e das sociedades.

É possível fazer uma tipologia da expectativa sob vários pontos de vista. Algumas palavras e expressões podem ser rotuladas de introdutores ou marcadores de expectativa. Elas podem ser classificadas de vários modos, por exemplo, de acordo com a categoria gramatical a que pertencem, como se mostra a seguir.

a) substantivos: expectativa, desejo, esperança, admiração, suspense, confiança, otimismo, desapontamento, ilusão, desilusão, previsão...

(21) A esperança é a última que morre.

(22) Meu desejo é viajar para a Europa.

(23) O otimismo econômico de João é antológico.

b) verbos: pensar, achar, desejar, esperar, admirar, iludir, acreditar, notar, ver, prever, lamentar, rejeitar, especular...

(24) Acredito que a economia se recupera rapidamente.

(25) Penso que vai chover.

(26) Maria admirava a honestidade do Prefeito.

c) adjetivos: inacreditável, inesperado, esperançoso, confiante, iludido...

(27) Aquele foi um presente inesperado.

(28) A chuva de ontem foi inacreditável.

(29) Marina estava esperançosa com relação à eleição.

d) advérbios: de repente, inacreditavelmente, inesperadamente, lamentavelmente...

(30) O acidente aconteceu de repente.

(31) Inesperadamente, começou a trovejar.

(32) Políticos corruptos agem lamentavelmente.

e) Conjunções: condicionais (se, caso, dado que, desde que), concessivas (embora, posto que, se bem que, apesar de que), temporais (quando, depois que, todas as vezes que, enquanto, até que), finais (para que, a fim de que)...

(33) Traga sua irmã, se você vier para a festa. (condicional).

(34) A inflação aumentou muito, se bem que o Governo avisou. (concessiva)

(35) Toda vez que chove, aparecem as goteiras na cozinha. (temporal) 
(36) Maria estava a fim de arrumar um namorado. (final).

Pode-se também ter categorias específicas, como se mostra abaixo:

f) Estrutura sintática e prosódica: sentenças incompletas (subordinadas), perguntas, asserções, avisos, igualdade matemática em fórmulas...

(37) Você comprou um novo computador?

(38) Como você conseguiu fazer tal bobagem?!...

(39) Dia de chuva é bom para tiririca!...

(40) $35 \%$ de $80=$ ?

g) Muitas expressões pragmáticas, como a pressuposição, os subentendidos e os atos de fala constroem-se sobre expectativas. Toda pressuposição (DUCROT, 1972), sendo um jogo semântico que exige conhecimentos prévios compartilhados, necessita da expectativa quer por parte do falante, quer por parte do ouvinte, como nos exemplos (41) e (42). Alguns verbos que introduzem pressuposição também são usados como introdutores de expectativas, como no exemplo (45):

(41) Rodrigo parou de fumar, mas não de beber. (fumava antes).

(42) Carlos parou de guiar carro. (guiava antes)

(43) Eu não sou o chefe?... (então, quem manda sou eu).

(44) Juro que não sabia de nada. (juramento).

(45) Helena pensa que viajará nas férias.

h) Os textos de autoajuda montam-se sobre certas expectativas, assim como certos textos religiosos. As expectativas podem, ainda, ser classificadas como voltadas para o bem (oxalá, Deus queira, sem dúvida), para o mal (infelizmente, duvido que, certamente não) ou indiferentes (eu acho que, eu penso que).

(46) Deus queira que a vida melhore.

(47) Duvido que Manuel encontre emprego.

(48) Eu acho que a carta chega hoje.

i) Situações discursivas dialógicas são construídas sobre um jogo de expectativas:

(49) Carlos: Agora o carro já partiu... O que você achou?

Maria: Helena não vai mais voltar para falar com você. Tenho certeza.

Carlos: Então, você acha que ela tinha mais alguma coisa a dizer? 
Maria: Se você não entendeu a situação, é inútil ficar arrependido agora.

j) A ideia de expectativa não é exclusiva de um falante ou de um ouvinte. Pode existir como um pensamento de um grupo de pessoas e de uma sociedade ou nação. Toda ideologia política, crença religiosa, moralismo, cultura e arte e até as leis carregam consigo fortes expectativas que unem as pessoas em torno de determinadas ideias e ideais. Não somos criadores dessas expectativas, mas apenas nos vemos envolvidos nelas. Existe uma mente coletiva que controla as dimensões dessas expectativas.

(50) A ideologia do Nazismo era compartilhada por muitas pessoas.

(51) Os metalúrgicos sempre acham que ganham menos do que deviam.

(52) A tradição brasileira espera que o carnaval seja uma grande festa.

k) O interlocutor pode também criar expectativas na sua mente, que não foram nem serão necessariamente pensadas pelo locutor. Por exemplo, o professor diz a nota e o aluno comenta explicitando sua expectativa:

(53) Professor: A nota da sua prova é 8,5.

Aluno: Eu pensava que ia ganhar 10, porque eu acertei todas as questões!?...

1) Como visto antes, a ideia de expectativa depende das expressões de tempo da linguagem. Sua formulação mental seja na mente do locutor seja na mente do interlocutor é sempre uma hipótese que remete ao passado ou ao futuro, nunca ao presente da enunciação. Quando ocorre uma expressão introdutora de expectativa, apesar de ocorrer um verbo no tempo presente, a ideia de expectativa é futura, como no exemplo (54), em que há uma expectativa positiva para o futuro. Mesmo ocorrendo o verbo no passado a localização da expectativa com relação ao tempo da enunciação situa-se no futuro, mas, neste caso, a expectativa é interpretada como frustação, como no exemplo (55):

(54) Há muita expectativa com relação à Petrobrás.

(55) Havia muita expectativa com relação à Petrobrás.

m) Os mal-entendidos podem ter vários tipos de causa, como a ambiguidade e a vagueza. Porém, quando provenientes de expectativas mal interpretadas, são mais sutis e mais difíceis de serem discutidos. Nestes casos, não basta discutir palavras, é preciso discutir intenções, como mostra a narrativa a seguir: 
(56) Ao ver a carta de motorista do filho, o pai fica surpreso e o filho não entende por que o pai queria que ele não tirasse carta de motorista de motos, mas apenas de carros. Volta à cena uma discussão antiga.

\section{Ainda sobre a natureza e funções da expectativa}

Nos exemplos acima, através de vários mecanismos linguísticos, podemos reconhecer nos enunciados que, além do sentido literal e de uma informação transmitida, esconde-se uma expectativa. É um sentido a mais que ocorre no processo de comunicação. Os exemplos acima mostram a ideia de expectativa na mente do falante e que ele espera esteja presente também na mente do seu interlocutor.

A expectativa se diferencia de outras formas de pensar e de transmitir ideias, como simples afirmações do tipo (57):

(57) Eu disse que Maria não virá à festa.

A declaração que Maria não virá à festa não é algo pressuposto pelo falante em sua mente, nem constitui um pressuposto na mente do ouvinte. Trata-se apenas de uma informação nova e explícita. Todavia, quando alguém fala, a expectativa acontece por outras razões, muito comumente sendo uma informação não revelada nem dita. Isso acontece com todo processo de comunicação, pelo menos como desejo do falante de dizer alguma coisa.

Todo falante espera que sua mensagem seja bem recebida como um ato de interação linguística e, se possível, com os sentidos que ele espera que seu interlocutor coloque em jogo para que a comunicação aconteça de modo correto, como desejado. Esses fatores são intrínsecos a todo ato de comunicação. No exemplo (57), o verbo dizer informa não pressupõe. Nesse sentido, é diferente de um verbo como eu penso que, eu acho que que, não só informa uma ideia, mas diz que essa ideia tem o valor de uma expectativa. Quando alguém diz (58):

(58) João disse que ama Maria.

não há expectativa mas uma declaração. Todavia, é muito estranho uma pessoa dizer um enunciado como (58) pelo simples fato de compor uma sentença da Língua Portuguesa. Por trás de tudo o que se diz, há uma intenção (expectativa do falante). Por outro lado, tudo o que uma pessoa ouve desperta nela não apenas as regras gramaticais e o sentido literal da sentença. $\mathrm{O}$ ouvinte também tem o direito de criar expectativas a partir do que ouviu. Por exemplo, ele pode se sentir 
rejeitado pela Maria. Embora de natureza linguística diferente, muitos fenômenos pragmáticos, motivados pelo literal, levam o falante e o ouvinte a acrescentar outras informações na própria mente, a que chamamos de conotações, ilações, etc.

A presença de uma expectativa não anula nem interfere em processos como a pressuposição, o acarretamento, os atos de fala, etc. Porém, como atividade mental, a expectativa precede a montagem das sentenças. Interpretações não ditas, mas pensadas, podendo ser ditas ou não, posteriormente, revelam que foram criadas antes de serem ditas em função de expectativas, caso contrário, não fariam sentido, seriam afirmativas muito estranhas, como quando alguém diz algo como (59), simplesmente como uma construção gramatical, uma declaração fora de um processo de interação.

(59) Maria vai se casar com João.

A partir da declaração em (59), nada impede que o ouvinte (ou mesmo o falante) tire conclusões não ditas, como (60)

(60) Maria é uma boba; João não presta, etc.

Essas conclusões vêm de expectativas com relação à Maria, ao João e ao casamento deles. Essas informações ficam restritas ao processo mental de cada um, podendo ser expressas em novas informações ou não num processo linguístico interativo.

A ocorrência de expectativas declaradas no discurso é muito comum e nem sempre nos damos conta delas. Conjunções como quando, se, etc. por formarem sentenças incompletas e subordinadas dependentes de uma sentença principal, trazem consigo uma expectativa sintática e semântica, como em (61) e (62):

(61) Quando você vier, traga uma garrafa de vinho.

(62) Se você tiver dinheiro, compre um apartamento na ilha.

Por outro lado, há enunciados que mostram que o falante ou o ouvinte jogam com ideias que precisam ser compartilhadas, mesmo que não sejam solicitadas através de palavras ou de expressões. Às vezes, a expectativa aparece num enunciado cujo resultado já é sabido. Ao dizer o enunciado abaixo (63), a pessoa já sabia que o time do Palmeiras foi mal e dá como explicação pela má atuação o fato (expectativa) de o técnico achar que o jogo seria fácil.

(63) Excesso de confiança foi o maior erro do técnico do Palmeiras.

O tipo de expectativa comentado acima acrescenta ao enunciado uma hipótese a ser testada. Essa hipótese não é estabelecida por uma relação de necessidade entre os dados linguísticos do enunciado e o que o falante e o ouvinte pensam. 
No exemplo (63), além da hipótese apresentada, poder-se-ia ter outras hipóteses, inclusive algumas oriundas de considerações semânticas específicas, que nada têm a ver com a ideia de expectativa.

A ideia de expectativa pode vir ligada a certas expressões que denotam hipóteses, crenças, crendices, fé, superstição, profecias, augúrios, provérbios...

(64) Tomar leite com manga faz mal.

(65) Deus queira que haja novas eleições sem breve.

(66) Água mole em pedra dura tanto bate até que fura.

Algumas afirmações trazem uma informação que não pode ser verificada cientificamente (com provas reais). Nestes casos, a expectativa associada ao enunciado é de inteira responsabilidade de quem acha que o enunciado é verdadeiro. Afirmações do tipo superstição estão no mesmo caso. A expectativa é afirmada como uma verdade que, de fato, não passa de uma hipótese. Outra fonte típica de expectativas são as crendices populares. Provérbios costumam ter a função de corrigir expectativas. Veja os exemplos a seguir:

(67) Os santos vão para o paraíso e os pecadores vão para o inferno.

(68) Um ramo de arruda atrás da orelha evita mau-olhado.

(69) Em casa de ferreiro, espeto é de pau.

Os provérbios são um tipo de pensamento muito comum na sociedade e mostram que, ao se dizer alguma coisa, além da verdade do enunciado (Em casa de ferreiro...), espera-se, como consequência lógica, uma conclusão específica (os espetos são de ferro...), num contexto normal da vida. Porém, tal expectativa é quebrada, com uma afirmação inusitada (... lá o espeto é feito de madeira!). Os provérbios são modos indiretos de significar para não dizer uma verdade nua e crua, que poderia ofender alguém.

A aceitação ou não de uma expectativa por parte do interlocutor, às vezes, depende da credibilidade de quem fala e das crenças e dos conhecimentos do interlocutor. Por causa disso, uma expectativa pode ser algo positivo ou negativo. A tendência geral é que os ouvintes e os leitores são levados a entender o que ouvem ou o que leem seguindo o sentido literal do texto, acrescentando sentidos não ditos. Porém, com relação às expectativas, cada um tem seu ponto de vista. Assim, uma manchete como (70) pode ser interpretada como uma expectativa de calamidade futura, por políticos que perderam a eleição para Dilma. Para seus amigos, a manchete simplesmente mostra que seu autor não conhece bem a Dilma, mas, certamente, seu governo será bom. 
(70) O governo da Dilma é uma incógnita.

Portanto, uma simples análise de como nos comunicamos linguisticamente mostra que estamos sempre fazendo hipóteses e introduzindo na mente dos nossos interlocutores algum tipo de expectativa, como se fosse uma desculpa prévia, se o que foi dito não se realizar, ou como um reforço argumentativo, a respeito de alguma coisa que, de fato, acabou acontecendo.

Os exemplos dados acima estão, de certo modo, ligados a alguma expressão da língua ou a algum mecanismo de significação. Através deles, pudemos ver que há um tipo de pensamento que não está grudado no significado das palavras. Essas expressões simplesmente sinalizam algo não dito, significam que há um vazio na mensagem, cujo conteúdo é preciso procurar e acrescentar ao sentido geral do enunciado. Porém, há ainda um tipo de expectativa que é mais radical com relação à sua não revelação através das palavras. É um pensamento fora das exigências lógicas e pragmáticas. É a expectativa que mora na mente do falante e do ouvinte, mas que não sai de lá. É uma expectativa que não dialoga com o mundo externo. É a expectativa no seu sentido mais restrito.

A expectativa mais típica é uma fonte autônoma de pensamento e que tem motivação própria, que gera hipóteses a partir de informações não expressas nos enunciados. Certamente, todo pensamento só existe quando linguisticamente formulado. Portanto, não há nada na mente em termos de pensamento e de conhecimento que não esteja codificado linguisticamente. Mas uma coisa é pensar e outra é falar tudo o que se pensou e como se pensou. Na sua gênese, pensamento e linguagem são a mesma coisa e o que chamamos de faculdade da linguagem é a nossa mente. $\mathrm{O}$ cérebro e todo o sistema nervoso são apenas captadores de informações externas que contribuem para o pensamento intelectual, processado na mente humana. Portanto, todo ato linguístico de falar e de entender depende crucialmente de como a mente da pessoa lida com a linguagem. Por outro lado, nossa habilidade linguística depende, ainda, dos conhecimentos que temos da língua que falamos ou ouvimos. Sabe-se por experiência própria que nem sempre falamos para outras pessoas o que pensamos. Existe um tipo de pensamento que nasce e fica na mente das pessoas. Os pensamentos mais típicos que guardamos na mente são as hipóteses a respeito de tudo, as quais acrescentam significados novos ao que já sabemos, constituindo novos pensamentos e que são exatamente as expectativas. Pensamos sempre agregando expectativas ao sentido literal ou aos pressupostos do que falamos e do que ouvimos. O discurso não começa e nem 
acaba nas palavras. Ele tem um toque individual de interpretação que damos ao que falamos e ao que ouvimos. Essa interpretação ou expectativa de interpretação, com o acréscimo de novos elementos é a maneira mais plena que temos de falar e de ouvir.

\section{Expectativa e frame}

Como foi dito no começo deste trabalho (TANNEN, 1979, p.179), a noção de frame é uma das mais antigas na Semântica Cognitiva. Nas últimas décadas, teve vários desdobramentos que mudaram, de certo modo, sua definição e função (FELTES, 2007, p. 135-140). A noção de script foi desenvolvida dentro de uma abordagem que era mais específica da ideia de frame. Lakoff (1987) desenvolveu vários modelos cognitivos idealizados que têm afinidades com a noção de frame de Fillmore (1982), em que algumas palavras são usadas e compreendidas num background prototípico. A noção de frame também dá suporte à ideia de blending, proposta por Fauconnier (1994). Certamente, a noção de cenário e de script são as que mais se aproximam da noção de frame associada à teoria da expectativa apresentada neste trabalho. O exemplo do script do restaurante (SCHANK, KASS, 1988) mostra uma expectativa coletiva, cultural. Nesse sentido, a palavra frame representa uma "moldura" e o conteúdo semântico que ela tem é um conjunto de informações sedimentadas culturalmente para a compreensão semântica e a vida em comunidade.

Essa visão mais geral da noção de frame já mostra que a ideia de expectativa deste trabalho tem peculiaridades que as noções tradicionais apresentadas acima não têm. Como ficou claro anteriormente, as expectativas nascem e vivem na mente dos falantes e dos ouvintes e são construtos pessoais, frutos do modo como nos relacionamos semanticamente com o pensamento que formamos na mente. Os conhecimentos de mundo, da cultura, das regras são apenas o lado externo da expectativa. O lado interno cada um sabe como é, mas ninguém precisa externá-lo nem quando fala. As peculiaridades desse frame são de domínio individual. É por isso que uma pessoa, mesmo vivendo em uma comunidade, pode interpretar certos fatos de comportamentos de modo muito idiossincrático, quase sempre chocando outras pessoas.

O objetivo do presente trabalho não é desenvolver as relações entre a ideia de expectativa e outras noções da Semântica Cognitiva, mas apresentar uma relação 
de fatos e de interpretações da linguagem que nos leva a ter uma teoria semântica específica para dar conta da natureza e das funções da ideia de expectativa. Um frame é dado externamente, e interpretado de modo semelhante a um script. A ideia de expectativa precede o uso da linguagem e é a base que justifica a origem da linguagem e de todo e qualquer ato de interação e de comunicação linguística.

\section{Conclusão: uma teoria da expectativa}

As considerações apresentadas trazem elementos para se construir uma teoria da expectativa, captando um sentido que, tradicionalmente, costuma aparecer misturado com outros. Essa é a razão pela qual esse aspecto do significado linguístico das palavras tem ficado pouco explorado e é, em geral, interpretado juntamente com outros sentidos que as palavras têm.

Numa primeira abordagem, podemos ver as expectativas: como ações do falante, quando ele tem a intenção de significar alguma coisa a mais, não dita, nem pressuposta, mas desejada; ou como expectativas do ouvinte / interlocutor, ou seja, da pessoa que vai interpretar algo processado, pensado e transmitido no processo comum de comunicação. Podemos fazer uma rápida busca por palavras que se caracterizam pelo fato de sinalizarem aos usuários que existe uma expectativa que vem em anexo, que indica que o falante tem algo a mais na sua comunicação, ou que o interlocutor procurou preencher, a partir de sua experiência linguística e de vida.

Um estudo preliminar com a teoria da expectativa que se apresenta neste trabalho poderia categorizar palavras e expressões adequadamente com relação ao fenômeno. Poderia explicar como a mente funciona através de estudos sobre como as línguas introduzem expectativas nos enunciados. Uma teoria da expectativa precisa lidar com um sistema complexo e com a entropia.

Em resumo, com o presente trabalho mostrou-se um fato semântico, definido como expectativa, que não se enquadra de modo adequado em nenhum rótulo tradicional da semântica. Trata-se de um significado que nasce na mente das pessoas sem estar ligado a um discurso já formulado. Portanto, é um sentido a mais que ocorre na comunicação entre pessoas ou apenas na mente de quem fala ou nas interpretações pessoais de quem ouve. É uma nova fonte de significação que só se revela quando expressa na fala, mas que pode ficar oculta na mente. É um pensamento que não precisa ser falado diretamente, mas que pode ser deduzido a 
partir de certos discursos e das circunstâncias em que um discurso acontece. Uma expectativa pode ser particular de uma pessoa ou pode existir numa sociedade, sendo compartilhada por grupos de pessoas.

A ideia de expectativa pode ser encontrada em quase todo tipo de enunciado ou de discurso. Essa noção está para a semântica cognitiva assim como a ordem está para a sintaxe. Nós só pensamos porque criamos expectativas. Esse é o segredo da comunicação verbal. Infelizmente, ela tem sido pouco estudada. Pode ser confundida com outras noções semânticas. A ideia de expectativa ajuda a dar sentido a muitas afirmações da Semântica Cognitiva, a começar, de novo, pelas metáforas e metonímias. Mas, isso requer pesquisas e estudos futuros.

\title{
On a theory of expectation
}

\begin{abstract}
This paper presents a new cognitive theory about the idea of expectation that is found in the linguistic process of communication. This idea is commonly present in conversations, dialogues, oral and written texts of all kinds. It is a common semantic fact in all types of language use. An overview of this semantic phenomenon clearly shows that the idea of expectation is much more important in the semantic studies than it has been thought. A deeper investigation reveals that language needs the idea of expectation as a necessary motivation in communicating processes. The natural languages have words and expressions with the function of introducing the idea of expectation in the communication process, such as expectation, I think that..., special syntactic and prosodic structures like questions. The expectation may be in the speaker's mind, in the hearer's mind or in the mind of everybody concerned with the process of communication. The expectation may also be a fact formally embedded in rules or part of cultural behaviour in society. The setting up of a theory of expectation became easier with the development of cognitive semantics in the past decades. The notion of frame is the best candidate to explain the idea of expectation.
\end{abstract}

Keywords: Expectation. Communication. Frame. Cognitive Linguistics.

\section{Referências}

ABREU, Antônio Suárez. Linguística Cognitiva: uma visão geral e aplicada. São Paulo: Ateliê Editorial. 2010. 
AUSTIN, J. L. How to Do Things with Words. Oxford: Clarendon Press. 1975.

AVERBECK, Josh. Irony and Language Expectancy Theory: Evaluations of Expectancy Violation Outcomes. In: Communication Studies v. 61, n. 3. 2010. Routledge. 356-372. DOI: 10.1080/10510971003776147. Disponível em: http:// www.researchgate.net/publication/233348928.

BAKHTIN, Mikhail Mikhailovitch. Estética da Criação Verbal. São Paulo: Livraria Martins Fontes. 1992 [Estetika Slovesnogo Tvortchestva. Mascou: Iskustvo. 1979].

BURGOON, M. Language expectancy theory: elaboration, explication and extension. In: BERGER, C. R.; BURGOON, M. (eds). Communication and Social Influence Processes. Michigan: Michigan State University. 1995. p. 29-51. BURGOON, M.; MILLER, G. R. (1985). An expectancy Interpretation of language and persuasion. In: GILES, H.; CLAIRE, R. St. (eds). Recent Advances in Language Communication and Social Psychology. London: Lawrence Erlbaum. 1985. p. 199-229.

BURGOON, M.; DENNING, V.P.; ROBERTS, L. A. (2002). Language and Persuasion In: DILLARD, J.P.; PFAU, M. (eds.). The Persuasion Handbook Developments in Theory and Practice. California: Sage Publications. 2002. p. 117-136.

CANÇADO, Márcia. Manual de Semântica: noções básicas e exercícios. Belo Horizonte: Editora UFMG. 2005.

CHOMSKY, Noam. Aspects of the Theory of Syntax. Cambridge MA: MIT Press. 1965.

CAGLIARI, Luiz Carlos. Elementos de Fonética do Português Brasileiro. São Paulo: Editora Paulistana. 2007.

CAGLIARI, Luiz Carlos (Org.). O Tempo e a Linguagem. São Paulo: UNESP Cultura Acadêmica. 2008.

DUCROT, Oswald. Dire et ne pas Dire: principes de semantique linguistique. Paris: Hermann. 1972.

EVANS, Vyvyan; GREEN, Melanie. Cognitive Linguistics: an introduction. Edinburgh: Edinburgh University Press. 2006.

FAUCONNIER, Gilles. Mental Spaces. Cambridge: MIT Press. 1994.

FAUCONNIER, Gilles. Mapping in Thought and Language. Cambridge: Cambridge University Press. 1999. 
FAUCONNIER, Gilles; TURNER, Mark. The Way We Think. New York: Basic Books. 2002.

FELTES, Heloisa P. M. Semântica Cognitiva: ilhas, pontes e telas. Porto Alegre: EDIPUCRS. 2007.

FERRARI, Lilian. Introdução à Linguística Cognitiva. São Paulo: Contexto. 2011.

FILLMORE, Charles J. Frame Semantics. In: LINGUISTIC SOCIETY OF KOREA (eds.). Linguistics in the Morning Calm. Seoul: Hanshin. 1982. p. 111137. Disponível em http://brenocon.com/Fillmore\%201982_2up.pdf. Acesso em 27 nov. 2015.

FILLMORE, Charles J.; ATKINS, B.T. Toward a Frame-based Lexicon: the semantics of risk and its neighbours. In: Frames, Fields and Contrasts. LEHRER, A.; E. F. KITTAY, E. E. (eds.). Hillsdale: Lawrence Erlbaum. 1992. p. 75-102.

GEERAERTS, Dick; CUYKEN, Hubert (ed.). The Handbook of Cognitive Linguistics. Oxford: Oxford University Press. 2007.

GRICE, Paul. Logic and Conversation. In: Studies in the Way of Words. Cambridge, MA: Harvard University Press. 1989. [reimpressão do manuscrito de 1967].

JOHNSON, Mark. The Body in the Mind: bodily basis of meaning, imagination and reason. Chicago: The University of Chicago Press. 1990.

IAGALLO, Patrícia Ormastroni. A Construção da Significação Linguística do Tempo em Língua Portuguesa: sistema cognitivo, estrutura conceptual e estrutura semântica. Tese (Doutorado). UNESP - FCL, Araraquara. 2014.

KÖVECSES, Zoltán. Language, Mind and Culture. Oxford: Oxford University Press. 2006.

LANGACKER, Ronald. Foundations of Cognitive Grammar. Stanford: Stanford University Press. 1987.

LAKOFF, George. Women, Fire, and Dangerous Things: with categories reveal about the mind. Chicago: The University of Chicago Press. 1987.

LAKOFF, George; JOHNSON, Mark. Metaphors we live by. Chicago: The University of Chicago Press. 1980.

LAKOFF, Robin Tolmach. The Language War. London: The University of California Press. 2000. 
LEVINSON, Stephen C. Pragmática. São Paulo: Martins Fontes. 2007.

LYONS, John. Semantics. Cambridge: Cambridge University Press. 1996.

MILLER, G. R. (1987). Persuasion, In: CHAFEE, Berger (ed.). Handbook of Communication Science. California: Sage Publications. 1987. p. 446-483.

PINKER, Steven. The Language Instinct: how the mind creates language. New York: Harper Perennial. 1995.

PLEBE, Armando; EMANUELE, Pietro. Manual de Retórica. São Paulo: Martins Fontes. 1992.

ROOT, Michael D. Speaker Intuitions. In: Philosophical Studies: An International Journal for Philosophy in the Analytic Tradition. v. 29, n. 4. Springer. 1976. p. 221-234.

SCHANK, Roger C.; KASS, Alex. Knowledge Representation in People and Machines. In: ECO, Umberto; SANTAMBROGIO, Marco; VIOLI, Patrizia (eds.) Meaning and mental representations. Indianapolis: Indiana University Press. 1988. p. 181-200.

SEARLE, John. The Rediscovery of the Mind. Cambridge, MA: Bradford Book / The MIT. Press. 1992.

TALMY, Leonard. Toward a Cognitive Semantics. Cambridge, MA: Bradford Book The MIT Press. 2000.

TANNEN, Deborah. (1979). What's in a Frame? surface evidence for underlying expectations. In: FREEDLE, Roy (ed.). New Directions in Discourse Processing. Norwood: Ablex. 1979. p. 137-181. Disponível em http://faculty.georgetown.edu/ tannend/TANNEN\%20ARTICLES/PDFs\%20of\%20Tannen\%20Articles/1979/ what's\%20in\%20a\%20frame.pdf. Acesso em 27 nov. 2015.

WILSON, Robert A.; KEIL, Frank C. (ed.). The MIT Encyclopaedia of Cognitive Sciences. Cambridge, MA: The MIT Press. 1999.

Submetido: 29/03/2016

Aceite: 06/09/2016 